\title{
A INTERFERÊNCIA DO BANCO MUNDIAL NO ENSINO SECUNDÁRIO BRASILEIRO: EXPERIÊNCIAS HISTÓRICAS E DESAFIOS ATUAIS
}

\author{
LA INTERFERENCIA DEL BANCO MUNDIAL EN LA ENSEÑANZA SECUNDARIA \\ BRASILEÑA: EXPERIENCIAS HISTÓRICAS Y DESAFÍOS ACTUALES
}

\author{
THE INTERFERENCE OF THE WORLD BANK IN BRAZILIAN SECONDARY \\ EDUCATION: HISTORICAL EXPERIENCES AND CURRENT CHALLENGES
}

\author{
Eliza Bartolozzi FERREIRA ${ }^{1}$ \\ Marilia FONSECA ${ }^{2}$ \\ Elisangela Alves da Silva SCAFF ${ }^{3}$
}

RESUMO: O texto objetiva analisar as interferências no ensino médio em relação às parcerias estabelecidas entre os governos brasileiros com o Banco Mundial. Sua escrita foi motivada pelas ações de contrarreforma do ensino médio adotadas pelo governo Temer (2016-2018) e o anúncio do financiamento do Banco na sua implantação. O texto foi desenvolvido no interior de uma rede de pesquisa a partir da análise de documentos primários produzidos pelo Ministério da Educação em suas parcerias com o Bird, no período da ditadura militar. São analisados documentos do período das contrarreformas do ensino médio realizadas pelo governo Cardoso (1995-2002) e pelo governo atual. Nossa intenção não é fornecer descrições e explicações exaustivas sobre as parcerias que envolvem as contrarreformas do ensino médio, mas construir hipóteses sugestivas e oferecer algumas conclusões provisórias, já que nesse momento não é possível obter um diagnóstico completo da nova parceria anunciada pelo governo brasileiro com o BIRD.

PALAVRAS-CHAVE: Ensino médio. Reforma-contrarreforma. Banco Mundial. Privatização educacional.

RESUMEN: El texto tiene como objetivo analizar las interferencias en la enseñanza media en relación a las alianzas establecidas entre los gobiernos brasileños con el Banco Mundial. Su elaboración fue motivada por las acciones de contrarreforma de la enseñanza media adoptadas por el gobierno Temer (2016-2018) y el anuncio del financiamiento del Banco en su implantación. El texto fue elaborado dentro de una red de investigación a partir del análisis de documentos primarios producidos por el Ministerio de Educación en sus alianzas con el BM en el período de la dictadura militar. Se analizan documentos del período de las

\footnotetext{
${ }^{1}$ Universidade Federal do Espírito Santo (UFES), Vitória - ES - Brasil. Professora Associada da Universidade Federal do Espírito Santo e do Programa de Pós-Graduação em Educação. Doutora em Educação pela Universidade Federal de Minas Gerais. ORCID: https://orcid.org/0000-0002-4100-9875. E-mail: eliza.bartolozzi@gmail.com

2 Universidade de Brasília (UnB). Brasília - DF - Brasil. Professora do Programa de Pós-Graduação da Faculdade de Educação da Universidade de Brasília. Doutora em Educação pela Université Paris Descartes, Paris V,, França. ORCID: https://orcid.org/0000-0002-3972-1556. E-mail: mariliasfonseca@gmail.com

3 Universidade Federal do Paraná (UFPR). Curitiba - PR - Brasil. Professora Associada da Universidade Federal do Paraná e do Programa de Pós-Graduação em Educação. Doutora em Educação pela Universidade de São Paulo. ORCID: https://orcid.org/0000-0002-7682-0879. E-mail: elisscaff@gmail.com
}

RIAEE - Revista Ibero-Americana de Estudos em Educação, Araraquara, v. 14, n. esp. 3, p. 1733-1749, out., 2019. e-ISSN: $1982-5587$. 
contrarreformas de la enseñanza media realizadas por el gobierno Cardoso (1995-2002) y por el gobierno actual. No es intención de este texto proporcionar descripciones y explicaciones exhaustivas sobre las alianzas que involucran las contrarreformas de la enseñanza media, sino construir hipótesis sugestivas y presentar algunas conclusiones provisionales ya que en ese momento no es posible obtener un diagnóstico completo de la nueva asociación anunciada por el gobierno brasileño con el BIRD.

PALABRAS CLAVE: Enseñanza media. Reforma-contrarreforma. Banco Mundial. Privatización educativa.

ABSTRACT: The text aims to analyze the interference in high school in relation to the partnerships established between the Brazilian governments and the World Bank. His writing was motivated by the counterreform actions of high school adopted by the Temer government (2016-2018) and the announcement of the Bank financing in its implementation. The text was developed within a research network based on the analysis of primary documents produced by the Ministry of Education in its partnerships with the Bird during the period of the military dictatorship. Documents from the period of high school counter-reforms carried out by the Cardoso government (1995-2002) and by the current government are analyzed. Our intention is not to provide exhaustive descriptions and explanations about partnerships involving high school counter-reforms, but to construct suggestive hypotheses and offer some tentative conclusions since at this point it is not possible to obtain a complete diagnosis of the new partnership announced by the Brazilian government with BIRD.

KEYWORDS: High school. Reform-counter-reform. World Bank. Educational Privatization.

\section{Introdução}

A contrarreforma do Ensino Médio, instituída pela Lei nº $13.415 / 2017$, é mais uma medida regressiva na educação brasileira que tem a potencialidade de provocar formas diversas de privatização da oferta dessa etapa da educação básica, como também retoma a dualidade na formação dos jovens (FERREIRA, 2017). O retrocesso instituído por essa contrarreforma se consolida de forma mais contundente em julho de 2017, mediante anúncio do governo brasileiro de parceria com o Banco Mundial a fim de obter financiamento para viabilizar a implantação da Lei $n^{\circ}$. 13.415/2017 nos estados da federação.

A decisão sobre o acordo foi publicado no Diário Oficial da União no dia 17 de julho de 2017 e o valor estimado dos investimentos é de US\$ 1,577 bilhão, sendo que US\$ 250 milhões poderão ser financiados em cinco anos pelo Bird (MEC, 2017), ou seja, pouco mais de $15 \%$ do valor total pactuado. De acordo com informe do MEC no dia 24/01/2018, os recursos 
estarão vinculados ao Programa para Resultados (PforR) ${ }^{4}$ e o Ministro afirma que o dinheiro será liberado por etapas, à medida que os planos de trabalho dos estados forem aprovados pelo Governo Federal.

O apoio financeiro da União será destinado à implantação do "Novo Ensino Médio", especialmente as ações de formação de técnicos educacionais para a adaptação dos currículos e elaboração dos itinerários formativos e distribuição de recursos para reprodução de materiais de apoio e para o incentivo à implementação dos novos currículos. Importante sublinhar, neste informe sobre a parceria com o Banco Mundial, a afirmação do Ministro de que parte dos recursos do empréstimo será destinada à assistência técnica ao MEC e às secretarias estaduais de educação de forma a permitir a contratação de serviços de consultoria especializados de alto nível. Esse foi o modelo largamente praticado em períodos anteriores da história da educação brasileira e, recentemente, no governo Cardoso (1995-2002).

$\mathrm{Na}$ sua essência, esse novo acordo remete ao histórico processo de ascendência internacional sobre a política educacional brasileira, com vistas à formação do trabalhador para o desenvolvimento econômico do país. Entre os atores internacionais que figuram nesse processo destaca-se o Banco Internacional para Reconstrução e Desenvolvimento, comumente referido como Banco Mundial ou Bird. Desde a década de 1960, o Banco vem estabelecendo parceiras com o Ministério da Educação, por meio de acordos de financiamento e cooperação técnica para a educação básica.

Este texto foi desenvolvido a partir da análise de documentos primários produzidos pelo Ministério da Educação em suas parcerias com o Bird, no período da ditadura militar. Ademais, foram examinados documentos oriundos do Ministério da Fazenda e do Banco Mundial, responsáveis, em última instância, para consolidar o parecer final sobre acordos, no que se refere ao desempenho físico e financeiro dos projetos. Foram ainda analisados documentos do período das contrarreformas do ensino médio realizadas pelo governo Cardoso (1995-2002) e pelo governo Temer (2016-2018). Não é intenção desse texto fornecer descrições e explicações exaustivas sobre as parcerias que envolvem as contrarreformas do ensino médio, mas construir hipóteses sugestivas e oferecer algumas conclusões provisórias já que nesse momento não é possível obter um diagnóstico completo da nova parceria anunciada pelo governo brasileiro com o BIRD.

${ }^{4} \mathrm{O}$ PforR vincula os repasses do empréstimo ao alcance de resultados, que são medidos por indicadores que serão acordados entre o MEC e o Banco. É por meio do PforR que o projeto pretende apoiar as secretarias estaduais e distrital de educação. 
Não obstante a vasta literatura já publicada a respeito do papel desempenhado pelo Banco Mundial na construção da agenda educacional brasileira, as informações agregadas a este artigo se justificam no atual momento em que o Banco Mundial, após quase 20 anos de ausência, ${ }^{5}$ assina um novo acordo de financiamento com o MEC em prol do ensino médio. Ao examinar o percurso da cooperação técnica do Banco fica evidente que os projetos financiados por mais de quatro décadas seguidas (1974-2010) apresentaram fracos resultados e pesados custos financeiros para o país (FONSECA, 2014).

Um dos fatores que explicam a continuidade da cooperação em período tão extenso pode ser a falta de transparência com respeito aos resultados dos projetos, o que impede a sua análise, pelos técnicos do MEC, ante a oportunidade de novos financiamentos. Os documentos oficiais que mostram o seu desempenho físico e financeiro encontram-se dispersos entre várias instâncias burocráticas, sendo possível acessá-los em sua totalidade se examinados no Banco Central, no Ministério da Educação e da Fazenda e na sede do Banco Mundial, em Washington. Vale mencionar o fato de que muitos documentos são protegidos pelo sigilo imposto aos acordos internacionais ${ }^{6}$. Esse é o motivo primordial para abordar, neste artigo, uma parte da história da cooperação técnica do Banco Mundial à educação brasileira.

\section{Presença do Banco Mundial na educação brasileira}

As origens do interesse do Banco Mundial pelo financiamento da educação no Brasil remetem diretamente à necessidade de formação de mão de obra para o mercado de trabalho. No final da década de 1960, o quadro de carência de mão de obra, especialmente no campo das engenharias, necessária para a construção de pontes, estradas, portos e estradas de ferro, direcionou o foco dos investimentos do Banco para a formação de capital humano (HEYNEMAN, 2007). Segundo esse autor, “entre 1962 e 1980 todos os investimentos do Banco Mundial em educação exigiam justificativas baseadas em formação de mão-de-obra para o mercado" (Ibid, p. 137).

${ }^{5}$ O último acordo entre o MEC e o BIRD foi firmado em 1998, durante a gestão de Fernando Henrique Cardoso (Fundo de Fortalecimento da Escola - Fundescola). Visava ao desenvolvimento do ensino fundamental das regiões Norte, Nordeste e Centro-Oeste (BRASIL, MEC; 2002). Por força do acordo com duração de dez anos, o Fundescola foi concluído em 2010.

${ }^{6} \mathrm{Na}$ verdade tais avaliações foram realizadas por instituições nacionais contratadas especialmente para isto, com recursos dos próprios projetos. Outras avaliações completas dos projetos são também realizadas pelo Banco, as chamadas "Project Complete Repport (PCR)". Acontece que tais avaliações são de conhecimento restrito ao próprio Banco ou Ministério, o que explica o difícil acesso a elas. Esse fato explica porque os acordos subsequentes sofreram as mesmas dificuldades que acometeram os seus antecedentes. 
Inicialmente, o financiamento do Banco priorizou a "educação secundária diversificada", caracterizada pela combinação entre formação acadêmica e manual. A concepção que embasa tal proposição encontra-se expressa no Sector Policy Paper, de 1974, que indica um desequilíbrio nos sistemas educativos dos países em desenvolvimento, centrados em habilidades literárias e gerais que não contemplam as habilidades relacionadas a trabalhos específicos. A partir dos empréstimos condicionados pelo Banco, a partir de então, "Desde Somalia a Indonesia, cada proyecto de educación secundaria financiado por el Banco incluía el trabajo del metal y de la madera para los chicos y ciencia doméstica para las chicas" (Ibid. p. 139).

No Brasil, embora o Banco Mundial tenha pouca participação no financiamento de Projetos voltados para a educação até a década de 1970, tais princípios foram também adotados pela United States Agency for International Development (USAID), agência vinculada ao Departamento de Estado Norte-Americano, a qual participou, na década de sessenta, da equipe de planejamento do MEC (EPEN). A parceria conhecida como MEC-USAID culminou com a reforma educacional brasileira, consolidada pela Lei n ${ }^{\circ}$. 5692/71. Foi instituído o ensino médio profissionalizante, estabelecendo-se a divisão do currículo escolar em 1 núcleo comum e parte diversificada, essa última destinada a atender as demandas locais de formação para o mercado de trabalho.

A inserção do Banco como agência financiadora da educação brasileira nos anos 1970 ocorreu por decisão do Departamento de Estado dos Estados Unidos. Motivado pela reação negativa contra a Usaid no âmbito de países da América Latina, o Presidente Nixon achou por bem transferir a cooperação financeira bilateral para o Banco Mundial. Como agência multilateral, esperava-se que o Banco pudesse exercer uma cooperação mais técnica do que política,.

O primeiro acordo de financiamento do Banco destinou-se ao ensino técnico. Assinado em 1971, já trazia a exigência de criação de órgãos especiais de gestão de projetos. Além de resguardar os princípios e as diretrizes educacionais do Banco, esses órgãos instituíram uma nova forma de gestão, denominada desenvolvimento institucional, que seguia a linha da modernização administrativa. Em 1974, foi assinado um segundo acordo de financiamento com o MEC que previa a cooperação direta do Banco com as secretarias estaduais de educação das regiões Norte e Nordeste, cuja intenção era executar uma ação de impacto voltada para o desenvolvimento institucional. O objetivo era introduzir, nas secretarias, os modelos de gestão e de planejamento para a implantação efetiva da Lei nº. 5692/71. 
$\mathrm{Na}$ evolução dos acordos com o MEC, o Bird passou a exigir a criação de órgãos especiais de gerência, como o Premen e o Prodem, além de outros que foram criados na década de oitenta. Além da criação de órgãos, o Banco exigia a contratação de equipes técnicas para a execução dos projetos. Os decretos governamentais $n^{\circ}$. 68681/71 e 1312/74 garantiam a prioridade do Tesouro Nacional para prover a contrapartida aos créditos do Banco, além de determinar medidas administrativas facilitadoras para o desenvolvimento de projetos internacionais, como a contratação de pessoal independentemente das regras da administração pública, por exemplo. Ao serem encerrados os acordos, esses órgãos foram paulatinamente extintos, deixando uma carga de prejuízos administrativos e financeiros para a gestão ministerial.

Os recursos para a implantação desse projeto vieram do Programa de Desenvolvimento do Ensino Médio (PRODEM), proveniente do acordo de cooperação entre o governo brasileiro e o Banco Mundial. O objetivo era priorizar o financiamento de programas e projetos voltados para a formação de mão-de-obra para o mercado de trabalho.

\section{Programa de Desenvolvimento do Ensino Médio (PRODEM) e Programa de Expansão e Melhoria do Ensino - PREMEN}

O Programa de Desenvolvimento do Ensino Médio - PRODEM - foi executado pelo Acordo MEC-BIRD I no 755 BR, de 21 de junho de 1971. Esse foi o primeiro projeto de educação e a primeira participação do Bird no financiamento de projetos educacionais no Brasil. No final de 1974 (27/12/1974), o Acordo 1067-BR transferiu a responsabilidade de execução para o Programa de Expansão e Melhoria do Ensino - PREMEN. Seu objetivo era servir de modelo para a implantação da reforma educacional preconizada pela Lei no . 5692/1971. Além do propósito de estabelecer um processo de desenvolvimento institucional nas secretarias estaduais de educação, o projeto desenvolveu outras ações: 1) expansão e melhoria da qualidade do ensino do sistema de educação dos estados participantes; 2) correção das desigualdades em oportunidades educacionais entre o Norte/Nordeste e o sul do país, ao nível da educação fundamental e secundária e, 3) redução das deficiências em técnicas de nível médio e mão-deobra qualificada.

Os estados participantes do projeto foram: Amazonas, Pará, Maranhão, Piauí, Rio Grande do Norte, Paraíba, Alagoas e Sergipe, sendo do $2^{\circ}$ grau a maioria das escolas atendidas. O projeto consistia das seguintes partes: 1) construção, mobiliário e equipamento escolar; 2) programa de treinamento intensivo para cerca de 2.200 professores e 300 administradores; 3) 
emprego de consultores especialistas e concessão de bolsas de estudos para treinamento; 4) pesquisa de instalações escolares e mapeamento escolar, estudos de pré-investimentos para a implementação da reforma educacional, particularmente nas áreas rurais.

A leitura do Relatório de Desenvolvimento do Projeto MEC-BIRD/Acordo 1067-BR (MEC-CEDATE, 1981), revela que o Acordo foi prorrogado até o mês de dezembro de 1982. Ou seja, uma distância de onze anos da assinatura do primeiro Acordo 755 BR transferido para o Acordo assinado em 1974. O Bird financiou o projeto com US\$23,5 milhões. O governo brasileiro, à época, comprometeu-se a pagar ao Banco $8 \%$ a.a. sobre os valores retirados periodicamente. Uma taxa de compromisso de $3 / 4$ de $1 \%$ a.a. era cobrada sobre o valor do empréstimo não utilizado (saldo do Banco).

De acordo com informações coletadas no Relatório acima citado, os estados apresentaram dificuldades no cumprimento financeiro de sua responsabilidade, sendo que alguns deles nada desembolsaram, por exemplo, o Piauí. O Acordo somente tomou impulso a partir de 1978, quando a maioria das construções entraram em execução, equipamentos foram comprados e foi iniciado o "treinamento" dos "recursos humanos".

No que tange à execução dos objetivos do Projeto, o Relatório informa que, em 1980, 46 unidades escolares deveriam estar funcionando, com 71.580 alunos de $1^{\circ}$ e $2^{\circ}$ graus atendidos em 2 turnos. Mas em 1981, apenas 28 escolas estavam funcionando. Devido a essa situação, o acordo foi prorrogado até 1982 e com aumento de suas metas: o número de vagas subiu para 80.760 e para 51 o número de escolas. No fim do prazo para encerramento do Acordo, apenas $57,68 \%$ do total das 80.760 vagas estavam realmente ocupadas. Certamente que havia diferenças nas taxas de atendimento entre os estados: Maranhão, por exemplo, apresentou uma taxa de $25,16 \%$ e a Paraíba tinha $98,75 \%$ de suas vagas ocupadas.

Além da apresentação dos dados quantitativos de alcance do projeto, o Relatório traz dados coletados por meio de questionário aplicado a 902 professores e 30 administradores das escolas atendidas pelo Acordo. Do total de professores, 724 (80\%) têm formação em nível superior. Desses, 298 receberam a sua formação profissional ministrada por universidades em convênio com o PREMEN, isto é, cerca de $40 \%$. Praticamente a mesma porcentagem se repete quando se trata dos cursos de aperfeiçoamento feitos pelos professores: somente $40 \%$ completaram o curso oferecido pelo PREMEN.

Ao longo dos 4 anos de funcionamento das escolas de $2^{\circ}$ grau (como eram denominadas as escolas secundárias) pertencentes ao Acordo, as habilitações mais procuradas foram Saúde e Construção Civil. Os diretores informaram que os alunos que concluíram suas habilitações básicas não competem no mercado de trabalho em igualdade de condições com os alunos 
egressos das escolas técnicas. De acordo com os diretores entrevistados, este é um fator que causa desinteresse na procura dessas habilitações. A equipe responsável pela elaboração do Relatório informou que não foi possível acompanhar a evasão e reprovação e, nos questionários aplicados aos diretores, as respostas foram "pouco significativas".

Dentre os 307 professores que informaram fazer uso dos laboratórios e das oficinas, $61 \%$ relataram a insuficiência do material lá existente para realização do trabalho. Em relação aos equipamentos e materiais disponíveis nas escolas, $64 \%$ dos respondentes consideraram que a sua quantidade não era adequada às atividades docentes e discentes. $56 \%$ dos professores afirmaram que não receberam treinamento necessário para a utilização dos equipamentos existentes. Sobre o prédio escolar, cerca de $60 \%$ responderam que, em relação à distribuição espacial, os ambientes estão mais ou menos relacionados entre si.

Os dados apresentados no Relatório de Desenvolvimento do Projeto MECBIRD/Acordo 1067-BR (MEC-CEDATE, 1981) evidenciam que os objetivos do projeto tiveram baixo alcance, o que pode ser confirmado pelos estudos de autores sobre a política educacional implantada pela Lei $\mathrm{n}^{\circ}$. 5.692/1971, que estabeleceu a profissionalização compulsória no ensino de $2^{\circ}$ grau e, com isso, todos passaram a ter a mesma trajetória escolar. Essas mudanças na organização do ensino médio foram realizadas sem consultas à sociedade, pois o tempo era de autoritarismo e cerceamento dos movimentos sociais. Saviani (1996) destaca que essa lei completou o ciclo de reformas educacionais destinadas a ajustar a educação brasileira à ruptura política perpetrada pelo golpe militar de 1964. Cunha (2014) mostrou que sua intencionalidade foi inibir a "corrida" para o ensino superior.

No decorrer da década de 1980, já sob a vigência do novo modelo de empréstimo (Policy Based Loans), foi executado outro projeto para o desenvolvimento do ensino industrial e agropecuário de nível médio (EDUTEC, Acordo n n 2366-BR). O objetivo era dar continuidade ao primeiro projeto executado na década de 1970 (Acordo 755-BR). O Edutec voltava-se para o desenvolvimento do ensino agrícola de nível médio (abrangendo 33 escolas técnicas) e o ensino industrial (envolvendo 17 escolas).

Apesar da experiência vivenciada pelo MEC com a execução do projeto anterior, o Edutec não logrou um bom desempenho, tanto na execução física como financeira. Segundo Fonseca (2014), as causas remetem às dificuldades operacionais, entre as quais podem ser citadas: a) dificuldades dos órgãos executores (escolas) no sentido de detectar a priori dificuldades operacionais e financeiras que pudessem emperrar as ações, entre elas a morosidade para licitar equipamentos internacionais (por exigência do Acordo), além da dificuldade de importação dos bens e de treinamento de pessoal técnico para sua utilização nas 
escolas; b) em consequência das dificuldades expressas no item "a", ocorreram atrasos na execução de ações e na comprovação de despesas por parte das escolas em tempo hábil para garantir o desembolso do Banco e também a contrapartida nacional; c) ausência e /ou atraso de respostas do Banco (solicitadas pela coordenação central do projeto, no Ministério), em tempo hábil para sanar dificuldades operacionais e acertar o ritmo dos projetos.

Outras dificuldades, segundo Fonseca (2014), emperraram a execução do Edutec. Os recursos nacionais para a contrapartida ao financiamento externo (que em tese deveriam ser equivalentes) foram bem superiores aos do financiamento do Banco. $\mathrm{O}$ crédito externo previsto era de $43 \%$ do total de recursos e a do Brasil 57\%. Efetivamente, o crédito do Banco alcançou apenas $22 \%$, e, obviamente, aumentou-se consideravelmente o montante da contrapartida brasileira (BRASIL/MEFP, 1989, p. 12).

O desequilíbrio entre crédito e contrapartida explica-se pelos problemas econômicos que afligiram o Brasil na década de 1980, impedindo a alocação de recursos para a contrapartida no prazo determinado pelo Acordo. Este fato motivou o atraso da execução dos Edutec e da execução das metas de construção, reforma e equipamentos. Segundo avaliação conjunta do MEC e do Ministério da Fazenda, devido a esses atrasos, a continuidade do projeto Edutec causaria aumento considerável dos seus custos. Por esta razão, o Acordo foi cancelado em plena fase de execução, tendo sofrido uma perda considerável de recursos já destinados ao projeto pelo Banco de, aproximadamente, US\$ 7 milhões.

Segundo as evidências aqui analisadas, grande parte das dificuldades financeiras decorrentes da execução dos projetos educacionais deveu-se ao modelo de execução de projetos e ao custo dos serviços do Banco. Contrariamente à ideia disseminada no senso comum, de que a ajuda do Banco para o setor social (saúde, educação, desenvolvimento agrário) se faz por meio de "créditos a fundo perdido" trata-se, na verdade, de empréstimos de porte comercial, sobre os quais recai o pagamento de serviços (juros e taxas), portanto, com o mesmo custo e o rigor operacional exigido para a área de infraestrutura. Por esta razão, a avaliação dos projetos financiados pelo Banco não pode deixar de considerar a relação custo-benefício.

\section{O retorno do Banco Mundial no Governo FHC: o PROEP}

Com a missão de ditar uma política educacional para o Brasil em consonância com os interesses neoliberais hegemônicos na década de 1990, o Banco Mundial interferiu nas reformas educacionais conduzidas pelo governo Cardoso (1995-2002). A partir de então, os acordos entre 
o governo brasileiro e o Banco, no campo da educação, se multiplicaram substancialmente, o que se evidencia pelo aumento significativo da dívida externa do país nas décadas de 1980 e 1990. Cruz (2003) explica que “em 1985 a dívida externa era de US\$ 105 bilhões de dólares e, mesmo tendo pagado US\$ 282 bilhões de juros e amortizações entre 1985 e 1998 (126 bilhões só de juros), em 1998, a dívida aumentara para US\$ 230 bilhões de dólares” (CRUZ, 2003, p. $58)$.

As prioridades do Banco se ampliaram mediante sua participação na Conferência Mundial de Educação para Todos, realizada em 1990 em Jomtien, na Tailandia, sob a coordenação da Organização das Nações Unidas para a Educação, a Ciência e a Cultura (UNESCO). A partir de então se expandiu o campo de atuação do Banco Mundial, bem como o volume dos empréstimos para a educação, na tentativa de liderar o movimento de "educação para todos". Os fatos revelaram sua contradição, uma vez que o Banco não abandonou a perspectiva de educação como motor do desenvolvimento econômico que, em si mesmo, é um projeto excludente.

A expansão da atuação do Banco Mundial no Brasil se evidencia tanto pela quantidade de Programas financiados como pela abrangência geográfica. Observa-se que, até a década de 1980, os Programas com financiamento do Banco abrangiam as regiões Norte, Nordeste e Centro-Oeste do País; já na década de 1990, passa a contemplar também as regiões Sul e Sudeste. Os Programas financiados nesse período foram: Inovações no Ensino Básico, desenvolvido no estado de São Paulo a partir de 1991; Projeto Fundescola, desenvolvido nas regiões Norte, Nordeste e Centro-Oeste do Brasil, desde 1991; II e III Projetos Nordeste de Educação Básica, implantados a partir de 1993; Projeto Qualidade no Ensino Público, proposto para o estado do Paraná, a partir de 1994; Projeto de Melhoria da Qualidade da Educação Básica, também desenvolvido a partir de 1994, em Minas Gerais; Projeto de Educação Básica, implantado no estado do Espírito Santo, desde 1995 (SCAFF, 2007).

No cerne da contrarreforma, esteve a política de mudança da oferta do ensino médio e da educação profissional institucionalizada pelo Decreto $n^{\circ}$. 2.208/97. Com fins de materializar a contrarreforma, foi criado o Programa de Expansão da Educação Profissional (Proep), em 1997.

O Proep contou com recursos do Banco Interamericano de Desenvolvimento (BID) mais os recursos internos (MEC e MTE). Seu objetivo foi financiar a expansão física da Rede de Educação Profissional, pública e privada, e fazer as adaptações necessárias à implementação da contrarreforma. Dessa maneira, visou à implantação da contrarreforma da Educação Profissional, especialmente no que diz respeito às inovações introduzidas pela legislação, 
abrangendo aspectos técnico-pedagógicos tais como a flexibilização curricular e a adequação à demanda, formação e avaliação por competências, aspectos de gestão que contemplem a autonomia, a flexibilidade, a captação de recursos próprios e a questão das parcerias, bem como a expansão da Rede de Educação Profissional mediante iniciativas do segmento comunitário.

Numa primeira etapa, o objetivo do Proep foi o financiamento de 250 projetos de Centros de Educação Tecnológica, cuja finalidade foi a transformação e a reforma de unidades existentes, ou a construção de novas unidades; $40 \%$ dos recursos do programa foram destinados às instituições públicas da rede federal e das redes estaduais; $60 \%$ para projetos do chamado "segmento comunitário", nos quais se incluem as iniciativas privadas (nessa categoria estão contemplados projetos de empresas privadas - educacionais ou não -, de associações patronais do campo industrial, agrícola e de serviços e do sistema $\mathrm{S}$, composto pelo SENAI, SENAC, SENAR e SENAT, ONGs e instituições escolares da esfera municipal).

A visível mudança na orientação da política federal em relação à Educação Profissional não a isentou de críticas. A contrarreforma implementada pelo MEC foi vista por muitos como um desmonte da rede federal existente, na medida em que deveria ampliar o acesso a um número maior de estudantes. Além disso, o financiamento das políticas sociais - acompanhamento e análise e expansão pelo setor privado foi considerado uma estratégia de afastamento do Estado de suas obrigações para com a educação.

No Relatório Anual de Avaliação (exercício 2002) do PPA “Avança Brasil” consta a inauguração/implementação, em 2002, de 84 Centros de Educação Profissional, nos três segmentos, totalizando 104 centros ao longo de cinco anos de execução. Nesse mesmo relatório foram descritas as dificuldades pelas quais vinham passando o programa devido às reduções e contingenciamentos de recursos (FERREIRA, 2010).

Dessa forma, o Proep pôde ser caracterizado como um programa de baixa execução; a média de execução de 2000 e 2001 foi de $75 \%$ do orçamento liberado. As restrições orçamentárias e financeiras ocorridas no exercício de 2002 diminuíram, ainda mais, o ritmo de investimento do programa: dos $\mathrm{R} \$ 50$ milhões aprovados no orçamento provindos do FAT, foram liberados apenas $\mathrm{R} \$ 20$ milhões; dos $\mathrm{R} \$ 162$ milhões do orçamento do BID, foram liberados somente $\mathrm{R} \$ 74$ milhões. O documento ainda afirma que no ano de 2003 o cenário iria piorar, pois dos $\mathrm{R} \$ 230$ milhões solicitados, a Lei Orçamentária aprovada no Congresso Nacional constava a liberação de apenas $\mathrm{R} \$ 73,5$ milhões em todas as fontes de financiamento.

Pode-se afirmar, assim, que o Proep foi uma política irrelevante para o País na medida em que seu impacto social, quantitativo e qualitativo, foi mínimo; a capacidade de financiamento era reduzida progressivamente em vista das prioridades do superávit fiscal e, por 
fim, não atendeu aos princípios pedagógicos de uma formação técnica integral da força de trabalho.

\section{Projetos em disputa pela educação no Brasil: movimento recente entre a inclusão social e atendimento explícito ao mercado}

Com a ascensão dos governos de orientação democrática-popular (2003-2015), os acordos educacionais com o Banco Mundial foram interrompidos. Estudo feito pelo BIRD ${ }^{7}$ sobre a educação brasileira desse período destacou os progressos alcançados nos últimos anos por meio de políticas continuadas e de reformas efetivas e duradouras, e dá como referência os resultados do Programa Internacional de Avaliação de Alunos (Pisa), de 2009, onde reconheceu que "o Brasil está entre os três países que mais evoluíram nos últimos anos, principalmente pela redução da distorção entre idade e série” (MEC, 2010). Nesse documento, o BIRD reconhece o esforço do governo brasileiro em acompanhar os processos de convergência educacional estabelecidos globalmente, mas omite que esse desenvolvimento foi alcançado sem a necessidade de parcerias com o Banco.

No modelo padronizado de reformas educacionais, desenvolvido globalmente, há uma centralidade na educação como fator de progresso econômico. A escolarização em massa, como ressaltado por Davies e Guppy (2012), tornou-se fundamental para o avanço de missões aceitas globalmente de justiça social e progresso, e para a promoção do desenvolvimento nacional, do progresso econômico e da integração social. Ou seja, o então Presidente Lula da Silva (20032010), enquanto governou seguindo as regras do capital para a inserção do país na globalização econômica, também seguiu o princípio moderno estabelecido mundialmente de promoção de esforços para garantir o direito à educação.

Desde 2003, no Estado democrático-popular, as políticas para o ensino médio foram centradas no estabelecimento de parcerias técnicas e financeiras entre a União e os estados regionais com vistas à implantação de aumento do tempo escolar e de um currículo construído pelas experiências juvenis com base nas Diretrizes Curriculares Nacionais (2012). O argumento neoliberal hegemônico que defende a necessidade de escolas adaptadas à sociedade do conhecimento conviveu com projetos educativos de variados tons, tanto de uma perspectiva de escola mais emancipatória quanto de escolas ajustadas aos interesses do mercado.

\footnotetext{
${ }^{7}$ Achieving World Class Education in Brazil: The Next Agenda. Disponível em: http://portal.mec.gov.br/ultimasnoticias/222-537011943/16156-banco-mundial-analisa-a-evolucao-e-os-desafios-da-educacao-brasileira. Acesso em 01/09/2017.
} 
Em 2016, em meio à heterogeneidade da oferta do ensino médio, o governo Temer encaminhou a Medida Provisória 746/2016 ao Congresso Nacional, sancionada como Lei nº. 13.415/2017. A partir de 2018, essa lei autoriza uma mudança da estrutura e do currículo do ensino médio para todas as escolas públicas e privadas do país. Em vez de uma organização única para todos, a lei instituiu cinco itinerários formativos independentes ${ }^{8}$. A contrarreforma propõe ainda o fomento à oferta do ensino médio em tempo integral, garantindo as transferências de recursos da União com a finalidade de prestar apoio financeiro aos estados e Distrito Federal no atendimento a essa demanda. Os recursos para a implementação da referida Lei são buscados por meio de financiamento do BIRD.

Nesse contexto de profundas mudanças políticas na condução do governo brasileiro, o BIRD firmou a Estratégia de Parceria de País (Country Partnership Framework ou CPF, na sigla em inglês) para o Brasil. Este CPF cobre um período de seis anos (anos fiscais de 2018 a 2023) e orienta o trabalho do Banco Internacional para a Reconstrução e o Desenvolvimento (BIRD), da Corporação Financeira Internacional (IFC) e da Agência Multilateral de Garantia de Investimentos (MIGA) no país, as duas últimas consideradas pelo Banco Mundial como "nossas duas instituições focadas no desenvolvimento do setor privado" (BIRD, 2017, p. 3). Essas três instâncias deverão trabalhar lado a lado para obter resultados tangíveis em gestão fiscal, proteção social, educação e saúde. ${ }^{9}$

No documento sobre a estratégia de parceria do Banco Mundial para o Brasil (20182023), a primeira referência feita foi sobre a questão educacional relacionada ao item do apoio do setor privado ao ajuste fiscal e à produtividade. Dessa forma, o Banco manifesta explicitamente seu interesse em "participar de projetos sociais - como habitação social ou educação - se o governo fornecer as condições estruturais" (BIRD, 2017, p.16). O documento informa ainda que tanto o setor privado como os representantes das Organizações da Sociedade Civil "[...] enfatizaram a necessidade de políticas educacionais com foco na aprendizagem ao longo da vida e na melhoria das habilidades relevantes para o trabalho" (BIRD, 2017, p. 16).

Sobre o objetivo que trata do aumento da eficácia da prestação de serviços na educação, o documento do Banco refere-se diretamente à contrarreforma do ensino médio desencadeada pelo governo de Michel Temer, considerada como uma âncora para as intervenções do GBM nesta área, podendo ser apoiada por uma operação P4R (BIRD, 2017, p. 22).

${ }^{8}$ Linguagens, Matemática, Ciências da Natureza, Ciências Humanas e Formação Técnica e Profissional.

${ }^{9}$ Disponível em: http://www.worldbank.org/pt/news/press-release/2017/07/13/brazil-world-bank-group-presentscountry-partnership-strategy. Acesso em 01 de setembro de 2017. 
O Banco também propõe a introdução de técnicas de gerenciamento baseadas em resultados, a promoção de modelos aprimorados de prestação de serviços, bem como a provisão do setor privado com o objetivo de dar suporte ao país para a redução dos gastos em programas de saúde e educação, considerando as restrições fiscais e as deficiências da gestão pública no País.

Tais direcionamentos vão ao encontro dos fundamentos da gestão do governo de Michel Temer no Brasil, explicitados no documento intitulado "Ponte para o Futuro" (PMDB, 2015). Os princípios descritos nesse documento estão perfeitamente alinhados à concepção de Estado mínimo, pelos quais a redução da intervenção do Estado na regulação da economia e na oferta de serviços públicos é combinada com a ampliação das parcerias entre Estado e Mercado, especialmente no que se refere à complementação da oferta de serviços públicos pelo setor privado, como explicita o mesmo documento.

As contrarreformas instituídas em parte dos países latino-americanos são orientadas pela School Based Management (SBM), às quais visam a descentralização da autoridade do governo central para o nível escolar, de forma a transferir a responsabilidade e a autoridade de tomada de decisão para diretores, professores, pais, estudantes e outros membros da comunidade escolar (BIRD, 2015).

Segundo Sabbi (2012), a participação do Banco Mundial (BM) e do Banco Interamericano de Desenvolvimento (BID) no financiamento da educação, coloca-os numa posição de liderança junto aos demais organismos financeiros internacionais. Somente o BM participou, na década de 1990, com 15\% dos empréstimos educacionais. Mas, segundo o autor, a contribuição mais importante do Banco Mundial deve ser seu trabalho de assessoria, concebido para ajudar os governos a desenvolver políticas educativas adequadas às especificidades de seus países. O financiamento do Banco, em geral, é delineado com vistas a influir sobre as mudanças nas despesas e nas políticas das autoridades nacionais, pois seus esforços financeiros representam somente cerca de meio por cento do total das despesas com educação nos países em desenvolvimento. Ou seja, o retorno da presença do Banco na educação brasileira, especialmente no ensino médio, vem firmar seu acento na necessidade de privatizar os serviços educativos como estratégia de abertura de mais nichos de mercado com vantagem competitiva para os negócios internacionais. 


\section{Considerações finais}

A parceria atual com o Banco Mundial apresenta condições semelhantes com os períodos anteriores, com o agravante de trazer novas dívidas para o Estado brasileiro e transferir a oferta do ensino médio para o setor privado. Além de intensificar a privatização da educação, o movimento que está em curso com a contrarreforma do ensino médio apresenta um elemento complementar de análise: parece haver um consenso entre os donos do poder de que a inclusão social de todos/as é uma meta que deve ser abandonada.

Pela análise aqui efetuada, ficou evidente que o financiamento do Banco Mundial é um processo complexo, que acarreta, além de altos custos financeiros para o setor educacional, um peso administrativo no âmbito de um ministério. O Banco é o primeiro interessado em realizar um acordo, de modo a garantir sua sobrevivência como agência de crédito. Na década de 1970, chegou a sofrer resistência por parte da equipe de planejamento do MEC (EPEN) no processo de negociação de um projeto para a educação fundamental do Nordeste. A negociação estendeuse no período de seis anos e o acordo foi assinado no ano de 1980, sob a denominação de Projeto de Educação para o Nordeste - Edurural/NE (BANCO MUNDIAL, 1989). O processo de financiamento do Banco é do interesse do setor econômico dos países financiados, visto que os créditos acarretam o ingresso de dólares para reserva de divisas e do equilíbrio da balança de pagamentos.

No âmbito do ministério, de estados e municípios, o aporte de divisas internacionais gera expectativas de prestígio político para os dirigentes, no sentido de contribuir para o aumento de recursos para a educação básica e também de acréscimos no salário do corpo técnico responsável pela administração do projeto. No âmbito escolar, viceja a expectativa de que os financiamentos constituam solução para problemas crônicos da escola, entre eles, evasão e repetência, existência de profissionais leigos, falta de materiais, equipamentos e espaço físico inadequados.

Conclui-se, pois, que a atual parceria do governo brasileiro com o Banco mundial não deve ser mais caracterizada como nos outros períodos históricos aqui estudados, centrada na necessidade de investimento na educação diferenciada para os mais pobres, que seriam destinados a uma ampla formação de mão-de-obra. Talvez essa premissa deva permanecer como retórica tão somente, pois o movimento que se apresenta deixa crer que a racionalidade dominante entende que escola deve ser para poucos, já que não há empregos para todos na sociedade do conhecimento. Ademais, parece que o entendimento é de que um grupo de estudantes menor e selecionado poderá apresentar melhores índices nas avaliações de larga 
escala, o que tende a melhorar a imagem do Brasil. Como efeito perverso, poderemos conviver com a desistência do direito à educação para todos, sem distinção de gênero, raça, e condição social, tão duramente conquistado na legislação e cuja caminhada estava apenas começando.

\section{REFERÊNCIAS}

BANCO MUNDIAL. Focus on poverty: a report. Washington, DC: Banco Mundial, 1983.

BANCO MUNDIAL. Northeast Basic Educatio Project. Project Complete Repport, Loan 1867-BR. Washington, DC: Banco Mundial, 1989.

BANCO MUNDIAL. Relatório Anual de 2016. Washington, DC: Banco Mundial, 2016.

BIRD. The International Bank for Reconstruction and Development. What Is SchoolBased Management? Washington, DC, WBG, 2017.

BIRD. The International Bank for Reconstruction and Development. Country partnership framework for the Federative Republic of Brazil for the period fy18-fy23. Washington, DC, WBG, 2017.

BRASIL. MEC. Fundescola: Boletim Técnico. nº 56, ano VII, Brasília, 2002.

BRASIL. Planejamento plurianual - relatório Anual de Avaliação (exercício 2001). Brasília, 2003.

CRUZ, R. E. Banco Mundial e política educacional: cooperação ou expansão dos interesses do capital internacional? Educar, Curitiba, n. 22, p. 51-75, 2003.

CUNHA, L. A. O legado da ditadura para a educação brasileira. Educação \& Sociedade. Campinas, v. 35, n. 127, p. 357-377, abr./jun. 2014.

FERREIRA, E. B. A educação profissional nos PPAs dos governos FHC e Lula. Educação e Realidade. Porto Alegre, v. 35, n.3, p. 215-236, 2010.

FERREIRA, E. B. A contrarreforma do ensino médio no contexto da nova ordem e progresso. Educação \& Sociedade. Campinas, v. 38, n. 139, p. 293-308, 2017.

FONSECA, M. A gestão da educação básica na ótica da cooperação internacional: um salto para o futuro ou para o passado? In: VEIGA, I. P. A. e FONSECA, M. (orgs.). As dimensões do Projeto Político-Pedagógico. Campinas: Papirus Editora, 2001.

MEC. Política para a educação profissional. Brasília, 2003.

MEC-CEDATE. Relatório de Desenvolvimento do Projeto MEC-BIRD/Acordo 1067-BR. Brasilia, DF, MEC, 1981. 
PMDB. Partido do Movimento Democrático Brasileiro. Uma ponte para o futuro. Brasília: PMDB, 2015.

SABBI, V. A influência do Banco Mundial e do BID através do Proep na reforma da educação profissionalizante brasileira da década de 1990. Curitiba, ANAIS IX Anped Sul, 2012.

SAVIANI, D. Política e educação no Brasil. Campinas: Autores Associados, 1996.

SCAFF, E. A. S. Planejamento da Educação e cooperação internacional: uma análise dos programas Monhangara e Fundescola. Tese (Doutorado em Educação) - Universidade de Sao Paulo, 2006.

\section{Como referenciar este artigo}

FERREIRA, E. B.; FONSECA, M.; SCAFF, E. A. S. A interferencia do Banco Mundial no ensino secundário brasileiro: experiências históricas e desafios atuais. Revista IberoAmericana de Estudos em Educação, Araraquara, v. 14, n. esp. 3, p. 1733-1749, out., 2019. e-ISSN: 1982-5587. DOI: 10.21723/riaee.v14iesp.3.12757

Submetido em: 25/03/2019

Revisões requeridas: 20/04/2019

Aceito em: 15/05/2019

Publicado em: 30/08/2019 